\title{
Measurement-based Modelling and Validation of PV Systems
}

\author{
Md. Masum H. Islam \\ Sasa Z. Djokic \\ Institute for Energy Systems, School of Engineering \\ The University of Edinburgh \\ Edinburgh, UK \\ sasa.djokic@ed.ac.uk
}

\author{
Jan Desmet \\ Bart Verhelst \\ Elektrotechnical Expertise Center of Howest \\ HOWEST Department GKG \& LEMCKO \\ Kortrijk, Belgium \\ jan.desmet@howest.be
}

\begin{abstract}
This paper presents the analysis and results of modelling of various photovoltaic (PV) systems. Two general models are discussed and presented: an analytical model and an equivalent circuit model, both formulated for main PV technologies currently available on the market. Analytical model does not require any $P V$ system specific input data or parameter, and is formulated as a generic performance model of a considered PV technology. Equivalent circuit model, however, requires specific input data and adjustment of the model parameters, in order to provide an accurate representation of a modelled PV system. The paper provides direct comparison of models based on manufacturer's specification data and available measurements, as well as the discussion of obtained results.
\end{abstract}

Index Terms-Measurement-based modelling and validation, photovoltaic (PV) systems and technologies.

\section{INTRODUCTION}

The Feed-in Tariff (FiT) scheme was introduced in the UK on the $1^{\text {st }}$ of April 2010 as a financial support for small-scale renewable and low-carbon electricity generation technologies with capacity less than $5 \mathrm{MW}$. In just two years, the total capacity of FiT confirmed and registered installations increased from $15.2 \mathrm{MW}$ in 2010 to more than $1 \mathrm{GW}$ (1090.8 MW, in 247,953 installations) at the end of the first quarter (Q1) of 2012, of which $999.9 \mathrm{MW}$ or $91.6 \%$ were photovoltaic (PV) systems, [1]. The total electricity generation from solar PV in the UK reached $173 \mathrm{GWh}$ in Q1 of 2012 (from $4 \mathrm{GWh}$ in Q1 of 2010), with about $95 \%$ of all PV installations being domestic/residential sub-4 kW systems, [2]. As the similar trends are observed for global installed PV capacity, which in 2010 reached nearly $40 \mathrm{GW}$ (an increase of $131 \%$ or $16.6 \mathrm{GW}$ from 2009 , and nearly seventeen times more than $2.4 \mathrm{GW}$ installed in 2007, [3]), this clearly suggests that correct models of various PV technologies are becoming increasingly important for the analysis of existing networks and, particularly, future power supply systems.

This paper presents the results of the research aimed at obtaining improved yet simple models of various PV technologies and systems. Two general models are discussed and compared: an analytical generic PV model, expressed through the corresponding exponential equations, and an equivalent circuit PV model, based on a simplified Shockley diode representation. Both models are formulated for four main PV technologies currently available on the market. Model parameters are adjusted using the manufacturer's specifications and available measurements at a test PV site in Belgium and then directly compared. The obtained results are discussed and main conclusions are provided.

\section{DEVELOPED PV MODELS}

Two methodologies for PV modelling, together with the developed corresponding PV models of main PV technologies and systems, are presented in this section.

\section{A. Analytical Generic PV Model}

In order to identify limited number of "generic PV models", which are capable of representing majority of micro and small scale PV ( $\mu \mathrm{PV})$ systems and technologies, a database containing more than 240 different PV systems from different manufacturers is established and analysed in [4]. This work resulted in the identification of four "generic $\mu \mathrm{PV}$ power curves", $\left(P_{G \mu P V 1}\right.$ to $\left.P_{G \mu P V} 4\right)$, which correspond to the four main PV technologies available on the market: monocrystalline, polycrystalline, thin film (amorphous) and thin film (high-efficiency), respectively. Their normalized electrical power outputs (per $\mathrm{m}^{2}$ of the panel/module area and including typical efficiency of the inverter used for grid connection) are analytically described by (1)-(4) and also shown as efficiency curves in Figure 1:

$$
\begin{aligned}
& P_{G \mu P V_{-} 1}=0.134\left(1-e^{-0.04 S_{i r}}\right) S_{i r r}, \\
& P_{G \mu P V_{-} 2}=0.136\left(1-e^{-0.04 S_{i r}}\right) S_{i r r}, \\
& P_{G \mu P V_{-} 3}=0.09\left(1-e^{-0.04 S_{i r}}\right) S_{i r r}, \\
& P_{G \mu P V_{-} 4}=0.163\left(1-e^{-0.04 S_{i r}}\right) S_{i r r},
\end{aligned}
$$

where: $S_{i r r}$ is the $\mu \mathrm{PV}$ panel's input solar irradiance in $\mathrm{W} / \mathrm{m}^{2}$, $P_{G \mu P V_{-} I}$ to $P_{G \mu P V_{4}}$ are electrical power outputs of the four 
generic $\mu \mathrm{PV}$ models, expressed in $\mathrm{W} / \mathrm{m}^{2}$ of the total PV panel area for given input solar irradiance.

When an aggregate mix of the above four generic $\mu \mathrm{PV}$ models is analysed, a "master generic $\mu \mathrm{PV}$ " power curve $\left(P_{G \mu P V} M\right)$ can be obtained, (4), based on the contributions of the four individual generic models to the aggregate PV generation mix. From the analysis of the PV database, the following percentage contributions are assumed for "master generic
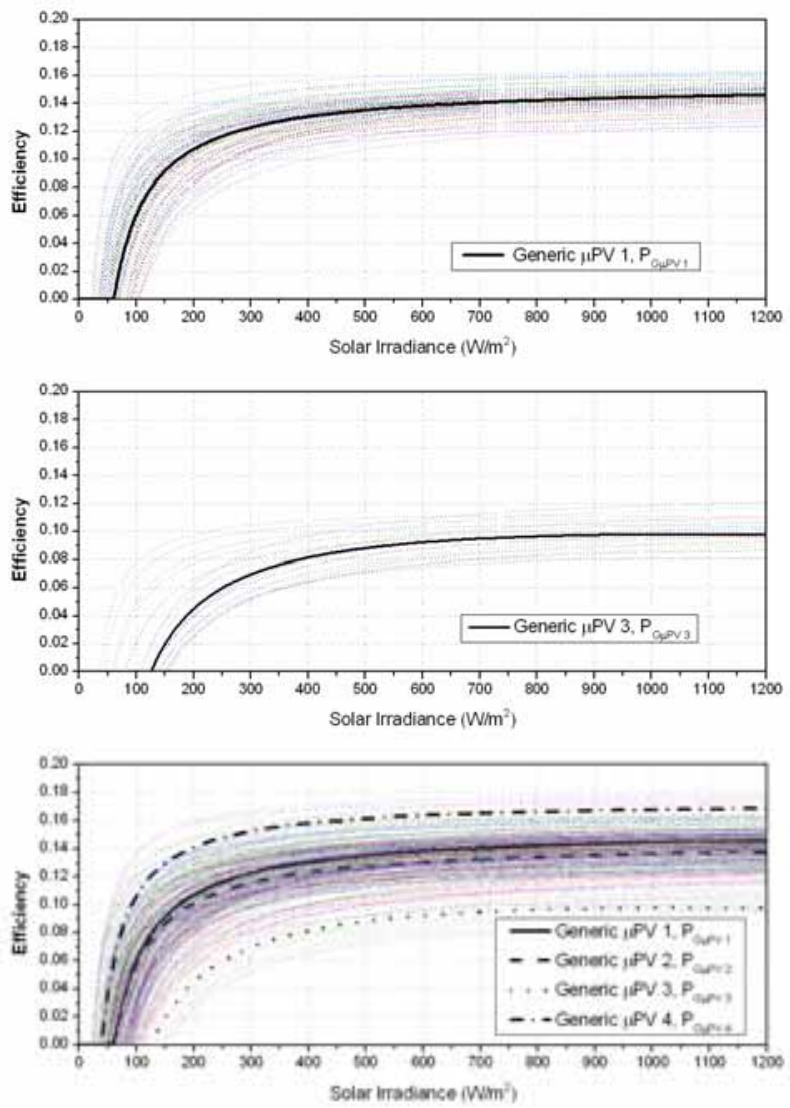

$\mu$ PV" model: Generic PV1 - 40\%, Generic PV2 - 43\%, Generic PV3 - 9\% and Generic PV4 - 8\%. Master generic $\mu \mathrm{PV}$ model is also shown in Figure 1:

$$
P_{G \mu P V_{-} M}=0.133\left(1-e^{-0.04 S_{i r r}}\right) S_{i r r},
$$

where: $P_{G \mu P V M}$ is electrical power output of the master generic $\mu \mathrm{PV}$ model, again expressed in $\mathrm{W} / \mathrm{m}^{2}$ of the total $\mathrm{PV}$ panel area for given input solar irradiance.
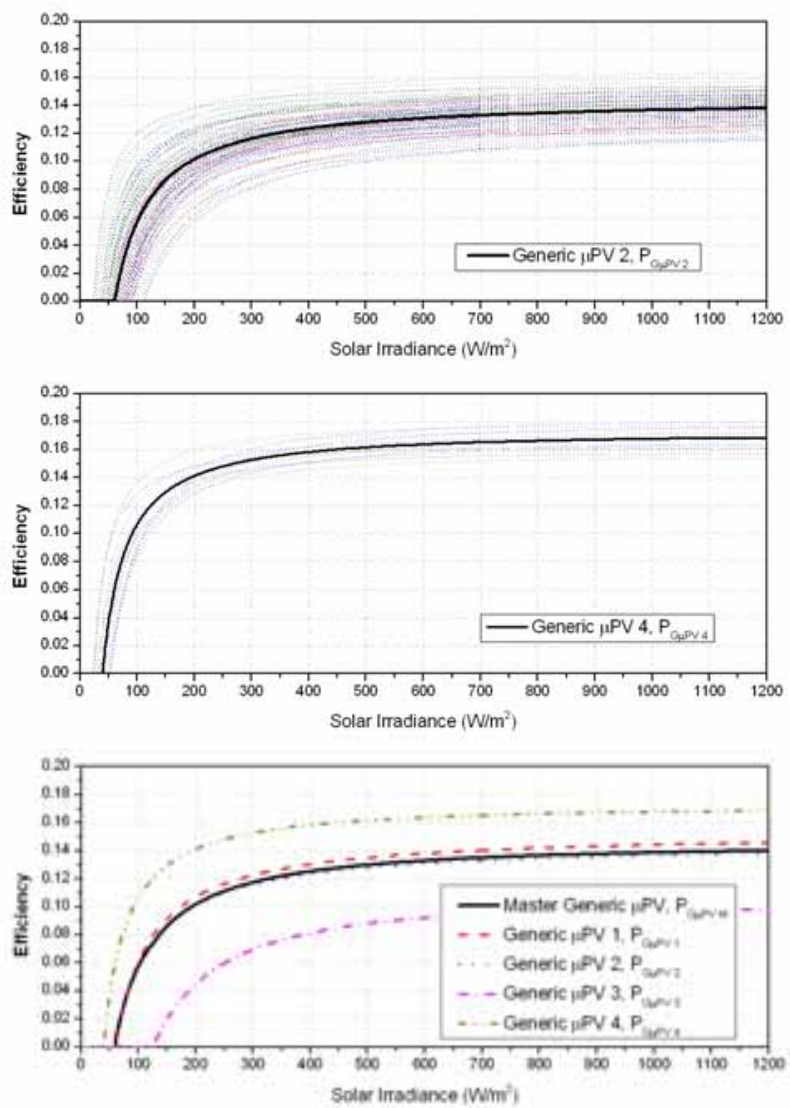

Figure 1. Comparison of the four generic, master generic and a number of actual $\mu \mathrm{PV}$ power curves, normalized using the corresponding PV panel areas.

\section{B. Equivalent Circuit PV Model}

PV panels are basically large areas made of p-n diodes (cells), capable of converting solar irradiance into direct current (dc) electricity, [3]. The basic equation (I-V characteristic) of the ideal PV cell is:

$$
I_{\text {out }}=I_{p v}-I_{d}\left(e^{\left(\frac{q V}{a k T}\right)}-1\right),
$$

where: $I_{o u t}$ is output dc current, $I_{p v}$ is photovoltaic current (proportional to input solar irradiance), $I_{d}$ is diode reverse saturation current, $q$ is the electron charge $\left(1.60217646 \times 10^{-19}\right.$ C), $V$ is voltage of the cell, $a$ is the diode ideality constant, $k$ is the Boltzmann's constant $\left(1.3806503 \times 10^{-23} \mathrm{~J} / \mathrm{K}\right)$ and $T$ is the temperature (in Kelvins) of the $\mathrm{p}-\mathrm{n}$ junction.

For a correct representation of the actual I-V characteristic of the real PV panel/array shown in Figure 2, the ideal PV cell equation (6) should be modified in accordance to, [5]:

$$
I_{\text {out }}=I_{p v}-I_{d}\left[e^{\frac{V_{\text {out }}+R_{s} I_{\text {out }}}{a V_{t}}}-1\right]-\frac{V_{\text {out }}+R_{s} I_{\text {out }}}{R_{p}},
$$

where: $V_{\text {out }}$ is output dc voltage, $V_{t}$ is thermal voltage ( $N_{s} k T / q$, for $N_{s}$ number of cells connected in series), $R_{s}$ represents equivalent series resistance and $R_{p}$ represents equivalent parallel resistance (losses due to recombination of charge carriers). If all the parameters are known, (7) can be used to produce the I-V curve/characteristic of any PV module. However, $R_{p}$ and $R_{s}$ are generally not known until a final PV array is designed and installed.

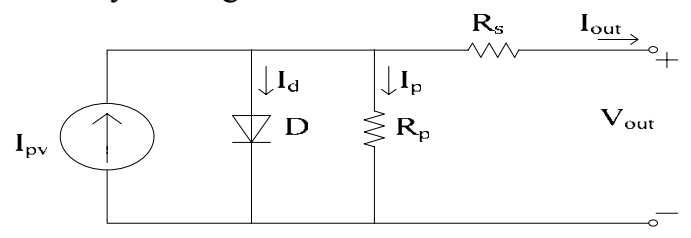

Figure 2. Equivalent circuit model of an actual PV cell. 
The manufacturers' datasheets provide information on the short circuit current, $I_{s c}$, which is the maximum current available at the PV cell terminals (assuming a very high value of $R_{p}$ and a very low value of $R_{s}$ ).

Under this condition, $I_{p v, n} \approx I_{s c}$, and photovoltaic current is:

$$
I_{p v}=\left(I_{p v, n}+K_{I} \Delta_{T}\right) \frac{S}{S_{n}},
$$

where: $I_{p v, n}$ is photovoltaic current measured for nominal or standard test conditions (STC, $25^{\circ} \mathrm{C}$ and $1000 \mathrm{~W} / \mathrm{m}^{2}$ ), $K_{I}$ is the temperature coefficient of $I_{s c}$ (given in either $\% / C$ or $m A /{ }^{\circ} C$, depending on the manufacturer), $\Delta_{T}$ is the difference between the actual temperature and nominal temperature $\left(T-T_{n}\right)$ in ${ }^{\circ} \mathrm{K}, S$ and $S_{n}$ are actual and nominal $\left(1000 \mathrm{~W} / \mathrm{m}^{2}\right)$ solar irradiance. The diode saturation current can be expressed as:

$$
I_{d}=\frac{I_{s c}+K_{I} \Delta_{T}}{e^{\left(\frac{V_{o c}+K_{V} \Delta_{T}}{a V_{i}}\right)}-1},
$$

where: $V_{o c}$ is open circuit voltage and $K_{V}$ is temperature coefficient of $V_{o c}$. The diode ideality constant, $a$, is an unknown parameter, as it is not given in the datasheets (usually $1 \leq a \leq 1.5$ ). The diode constant affects the shape of the I-V curve and can be altered to tune the PV model and match the output of a real PV system. Two unknown parameters, $R_{p}$ and $R_{s}$, can be calculated using the iterative method described in [5] by making $P_{\max , m}=P_{\text {max.e }}$ at the maximum power point (MPP) of the I-V curve:

$$
P_{\max m}=V_{m p p}\left\{I_{p v}-I_{d}\left[e^{\left(\frac{q\left(V_{m p p}+R_{s} I_{m p p}\right)}{k T a N_{s}}\right)}-1\right]-\frac{V_{m p p}+R_{s} I_{m p p}}{R_{p}}\right\}=P_{\max e}
$$

where: $P_{\max , m}$ is the maximum power output calculated by the I-V model described by (7), $P_{\text {max.e }}$ is the maximum power output given in the datasheet, or measured in actual installation, $V_{m p p}$ is the maximum power point voltage $(\mathrm{V})$ and $I_{m p p}$ is the maximum power point current (A). This equation can be solved iteratively to obtain values for $R_{s}$ and $R_{p}$ (e.g. by assuming $R_{s}=0$ as the initial value).

\section{MODELLING OF PV PANELS}

Analytical models presented in Section II.A with (1)-(4) do not require any PV panel specific input data or parameters. They are formulated as the generic (i.e. average) performance models of four main PV technologies, and are particularly suitable for the analysis of the impact and effects of a large number of PV systems and installations. These models can be easily aggregated to provide a simple and correct representation of power outputs of a specific mix of different PV technologies, as given by (5), and then used in various power system studies (e.g. [6]-[8]).

On the other hand, equivalent circuit model presented in Section II.B with (6)-(10) requires specific input data and parameters, as well as the adjustment of the other model parameters, in order to provide an accurate representation of a modelled PV system. Due to its simplicity and ability to correctly represent different PV technologies, this model is one of the most commonly used for the analysis (e.g. [9][12]). However, in the majority of the previous work, this model and its parameters are derived using the manufacturers' specification datasheets of the considered PV panel (e.g. [11][12]), while it was not clarified how the model can be used for the further analysis of the actual field PV applications and what adjustment, if any, would be required. The analysis presented in the further text directly compares the results obtained when the equivalent circuit PV model is derived based on the manufacturer specification data and when the model is readjusted based on the actual field measurements.

\section{A. PV Model Based on Manufacturer Specification Data}

The PV panel from [13] is considered for the analysis in this section, as it was one of the four PV technologies installed at a test site in Belgium, [14]. For this PV panel, the equivalent circuit model is derived to closely match the corresponding data given in the manufacturer's specification. The results illustrated in Fig. 3a (I-V characteristic of the PV panel) confirm that the model can provide an almost exact match with the manufacturer's data for a set of model parameter values given in Table I. The further results in Figure $3 \mathrm{~b}$ provide a more detailed information on the characteristics of a modelled PV panel for a range of input solar irradiance values and various temperatures of the panel.
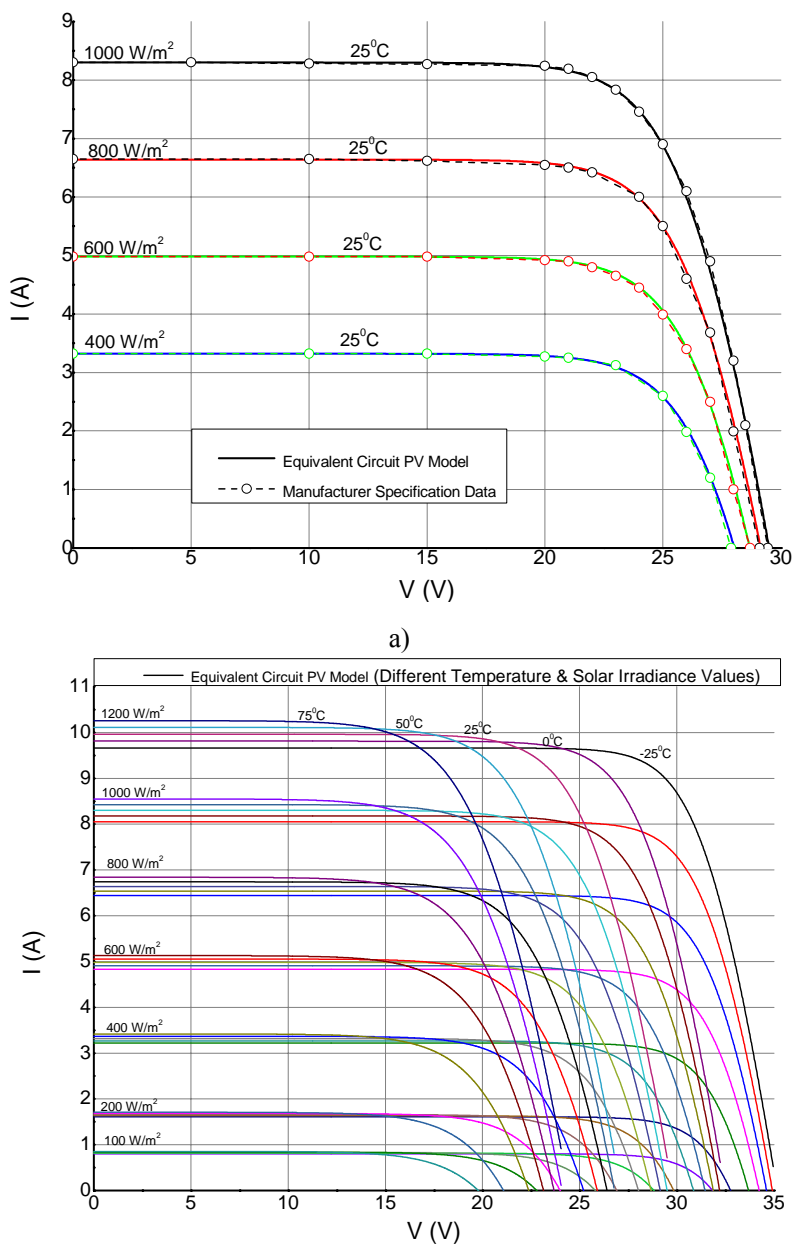

b)

Figure 3. The I-V curves of equivalent circuit PV model obtained using the manufacturer's specification data, [13]. 
TABLE I PARAMETERS OF THE EQUIVALENT CiRCUIT PV MODEL DERIVED FROM THE MANUFACTURER'S DATA $\left(\mathrm{T}=25^{\circ} \mathrm{C}\right)$

\begin{tabular}{|c|c|c|c|c|}
\hline \multirow{2}{*}{$\begin{array}{c}\text { Model } \\
\text { Parameter }\end{array}$} & \multicolumn{4}{|c|}{ Input Solar Irradiance, $S_{\mathrm{irr}},\left(\mathrm{W} / \mathrm{m}^{2}\right)$} \\
\hline & 1000 & 800 & 600 & 400 \\
\hline $\mathbf{a}$ & 1.3 & 1.3 & 1.3 & 1.3 \\
\hline $\operatorname{Rp}(\Omega)$ & 275 & 198 & 146 & 129 \\
\hline $\operatorname{Rs}(\Omega)$ & 0.22 & 0.19 & 0.14 & 0.129 \\
\hline$I_{0}(A)$ & $8.47 \mathrm{e}-8$ & $8.47 \mathrm{e}-8$ & $8.47 \mathrm{e}-8$ & $8.47 \mathrm{e}-8$ \\
\hline Ipv (A) & 8.3 & 6.65 & 4.989 & 3.32 \\
\hline Pmax_m (W) & 180.4 & 143.7 & 106.4 & 71.9 \\
\hline Vmpp (V) & 23 & 23 & 23 & 23 \\
\hline Impp (A) & 7.83 & 6.25 & 4.65 & 3.13 \\
\hline Isc (A) & 8.3 & 6.64 & 4.98 & 3.32 \\
\hline $\operatorname{Voc}(V)$ & 29.5 & 29.13 & 28.67 & 28.03 \\
\hline
\end{tabular}

\section{B. PV Model Based on Measurement Data}

For the validation of the previously described analytical and equivalent circuit PV models, i.e. for obtaining or adjusting required model parameters, measurements from a test PV site in Belgium (at LEMCKO Energy and Power Quality Lab, [14]) are used. At this site, four main PV technologies: monocrystalline, polycrystalline, thin film (amorphous) and thin film (high-efficiency) were installed in three different configurations: open, closed and tracker. The closed configuration is a fixed PV array installation, tilted at a suitable angle with the back of the PV panels enclosed, therefore preventing cooling by air. The open configuration is similar to the closed one, except that the back of the PV panels is open and exposed to air, allowing for convection cooling. The tracker configuration utilizes a light sensor controller, in order to maximize incident solar irradiation on the PV arrays.

The data collected from the test site for various PV configurations contains measurements of solar irradiance, ac output power, temperature, wind speed, and time/date of recordings. The measurements were recorded simultaneously for four PV technologies in all configurations in regular five minutes intervals. The measurements were collected over a period of two years, from September 2010 to September 2012, and these data are used in this section to re-adjust the equivalent circuit PV model developed in previous section using the manufacturer specification.

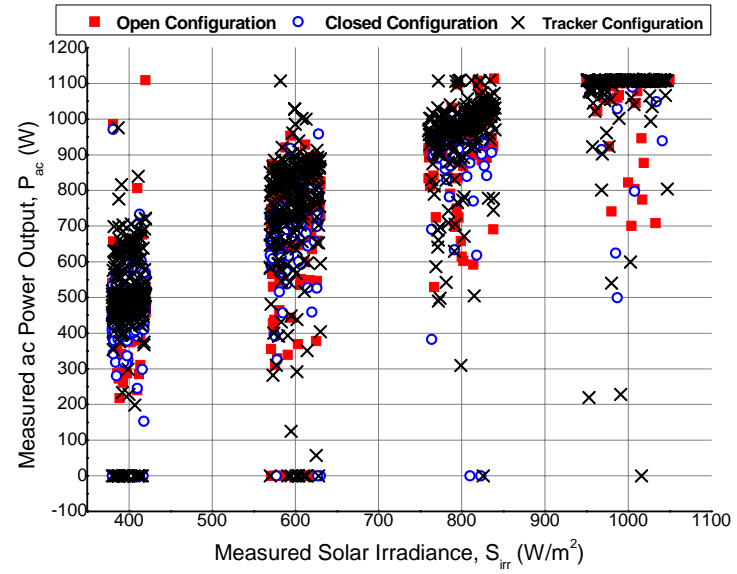

Figure 4. Measured ac power outputs for input solar irradiance $\left(\mathrm{S}_{\mathrm{irr}}=400 /\right.$ $\left.600 / 800 / 1,000 \pm 5 \% \mathrm{~W} / \mathrm{m}^{2}\right)$, temperature $\mathrm{T}=25 \pm 1^{\circ} \mathrm{C}$, no wind speed $(<1 \mathrm{~m} / \mathrm{s})$ and three configurations of a PV panel from [13].
The manufacturer of PV panel [13] provided specification data for closed configuration, no forced cooling, temperature of exactly $25^{\circ} \mathrm{C}$ and adjusted input solar irradiance values of $\mathrm{S}_{\text {irr }}=400 ; 600 ; 800$; and $1,000 \mathrm{~W} / \mathrm{m}^{2}$, Figure $3 \mathrm{a}$. Therefore, the measurements that closely correspond to these conditions $\left(\mathrm{T}=25 \pm 1{ }^{\circ} \mathrm{C}\right.$ and $\mathrm{S}_{\mathrm{irr}}=400 \pm 5 \%, 600 \pm 5 \%, 800 \pm 5 \%, 1,000 \pm 5 \%$ $\mathrm{W} / \mathrm{m}^{2}$ and wind speed less than $1 \mathrm{~m} / \mathrm{s}$ ) are extracted from the available 2-year recordings for all three configurations (open, closed and tracker) of a PV panel [13]. The raw measurement data, shown in Figure 4 for series connected seven panels, are then processed, in order to remove "outliers" (too high, or too low measurements due to data logging problems and errors) and to recalculate measured ac powers to actual output dc powers and currents/voltages of the PV panel. Additionally, inverter manufacturer's specification $([15])$ is used to estimate the average inverter's efficiency (92\%), assuming that inverter will control and operate PV panel around the maximum power point (MPP). Processed measurement data, corresponding to dc power outputs of a single PV panel operated in closed, open and tracker configurations, are shown in Figure 5.

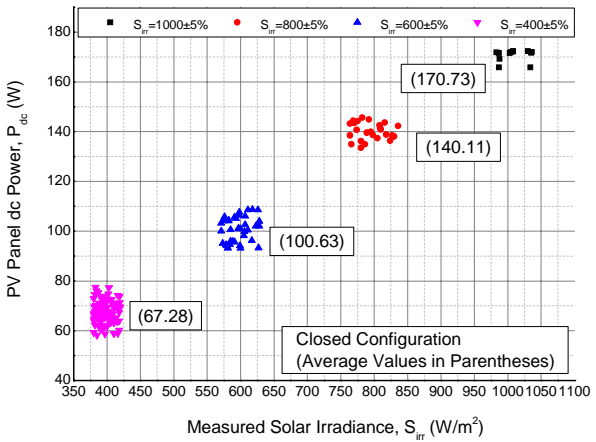

a)

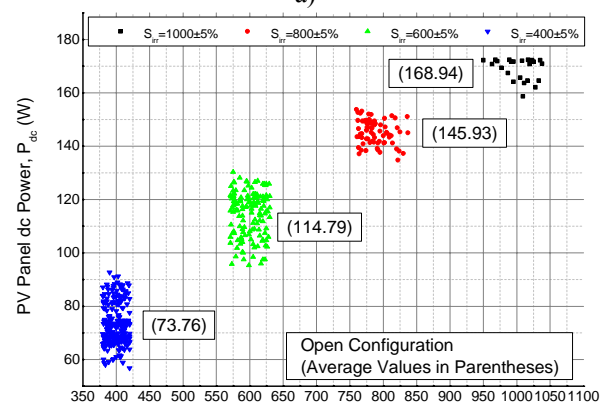

Measured Solar Irradiance, $\mathrm{S}_{\text {iff }}\left(\mathrm{W} / \mathrm{m}^{2}\right)$

b)

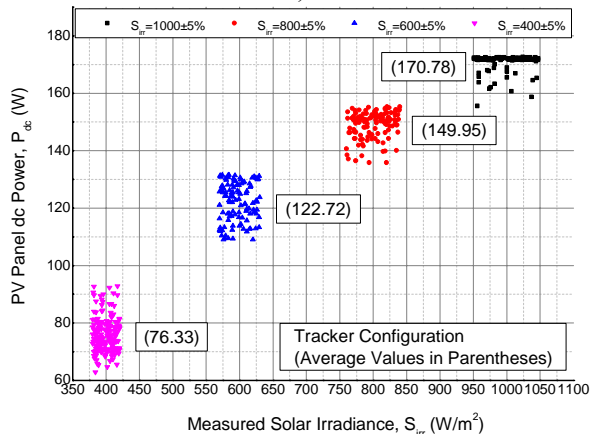

c)

Figure 5. Calculated dc power outputs of a single PV panel: a) closed configuration, b) open configuration, and c) tracker configuration. 
The results in Figure 5 show that for the same values of temperature $\left(\mathrm{T}=25 \pm 1^{\circ} \mathrm{C}\right)$ and input solar irradiance $\left(\mathrm{S}_{\mathrm{irr}}=400 \pm 5 \%, 600 \pm 5 \%, 800 \pm 5 \% \mathrm{~W} / \mathrm{m}^{2}\right), \mathrm{PV}$ panel will produce higher power output in tracker configuration, than in open configuration, than in closed configuration. It can be also seen from Figure 4 that for $\mathrm{S}_{\mathrm{irr}}=1000 \pm 5 \% \mathrm{~W} / \mathrm{m}^{2}$, the inverter control will limit power output below the rated power of the inverter $\left(\mathrm{P}_{\mathrm{ac}}=1100 \mathrm{~W}\right)$.

Table II lists the parameters of the equivalent circuit PV model for all three configurations, after they are adjusted using the measured data.

TABLE II. PARAMETERS OF THE EQUiVALENT CiRCUIT PV MODEL DERIVED FROM THE MEASUREMENT DATA $\left(\mathrm{T}=25 \pm 1^{\circ} \mathrm{C}\right)$

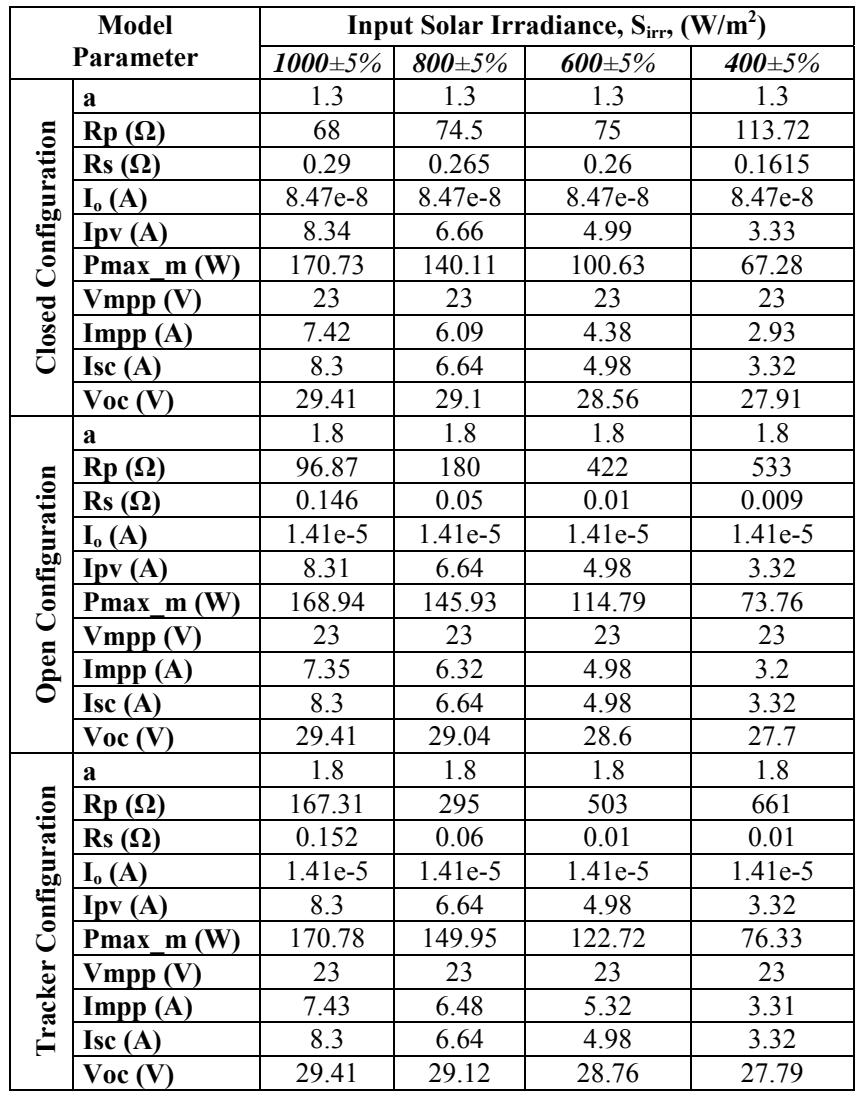

IV. COMPARISON OF RESUlTS FOR DIFFERENT PV MODELS

This section compares the results obtained using the previously discussed analytical and equivalent circuit PV panel models for the considered PV panel. Analytical model provides only PV panel power outputs and efficiencies (as a function of input solar irradiance), while equivalent circuit model can provide all PV panel characteristics and can be adjusted for the actual field application using the available measurements for closed, open and tracker configurations.

\section{A. Comparison of the I- $V$ curves}

The corresponding I-V curves for the equivalent circuit PV models adjusted using the measurements in all three configurations are illustrated in Figure 6. It can be seen from Figure 6a that considered PV panel in closed configuration produces lower power outputs than what is suggested by the model based on the manufacturer's specification data. On the other hand, the power outputs of the modelled PV panel will increase in open configuration and even more in tracker configuration (except when inverter limits PV panel power outputs below its rated power).

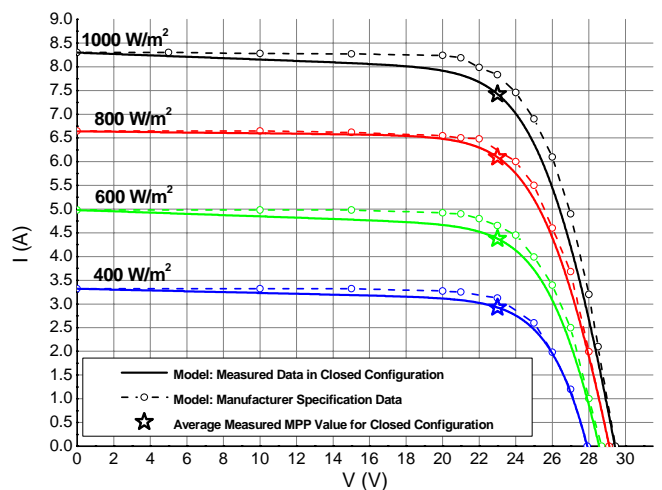

a)

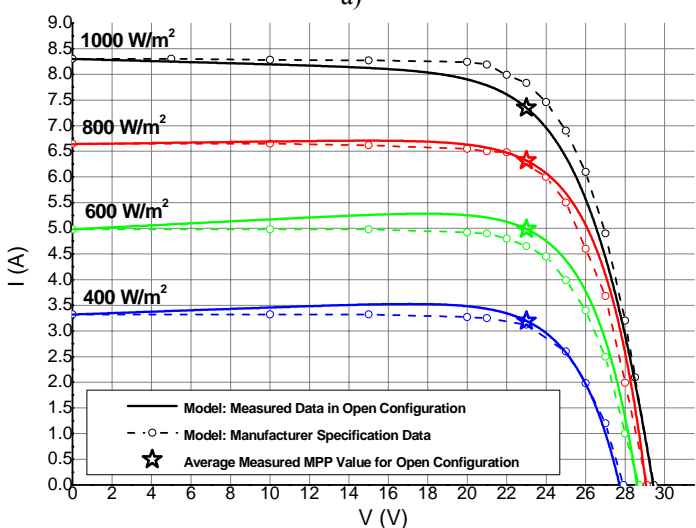

b)

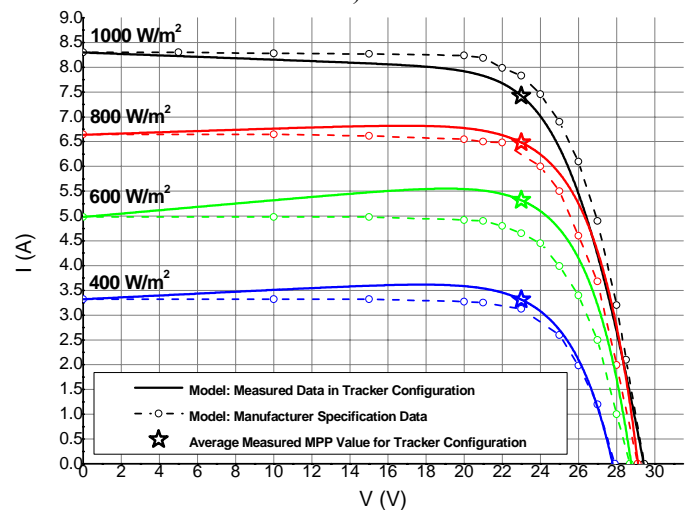

c)

Figure 6. Comparison of I-V curves for model adjusted based on manufacturer specification data and based on measurements: a) closed configuration, b) open configuration, and c) tracker configuration.

\section{B. Comparison of the Efficiency Values}

One of the most important characteristics of the PV panels is their efficiency as a function of input solar irradiance, expressed per $\mathrm{m}^{2}$ of the panel area. This information is crucial in selecting optimal PV panel for a given application, where available local solar irradiance levels at a roof or wall areas dedicated for PV installation, as well as the capital costs and tariffs, are used to assess the annual power/energy outputs and to estimate the expected pay-back period of the investment. 
Table III compares the calculated efficiencies of the considered PV panel [13], obtained using the corresponding analytical models given by (2) and (5) and equivalent circuit models adjusted using the manufacturer's specification data and available measurements for closed, open and tracker configurations.

TABLE III. EFFICIENCIES OF THE PV PANEL [13] FOR DIFFERENT INPUT SOLAR IRRADIANCE VALUES CALCULATED USING THE ANALYTICAL AND EQUIVALENT CIRCUIT MODELS

\begin{tabular}{|c|c|c|c|c|}
\hline \multirow{2}{*}{ Model } & \multicolumn{4}{|c|}{ Input Solar Irradiance, $\left.\mathbf{S}_{\text {irr }}, \mathbf{( W / \mathbf { m } ^ { 2 }}\right)$} \\
\cline { 2 - 5 } & $\mathbf{1 0 0 0}$ & $\mathbf{8 0 0}$ & $\mathbf{6 0 0}$ & $\mathbf{4 0 0}$ \\
\hline $\begin{array}{c}\text { Analytical } \\
\text { Equation (2) }\end{array}$ & $13.6 \%$ & $13.6 \%$ & $13.6 \%$ & $13.6 \%$ \\
\hline $\begin{array}{c}\text { Analytical } \\
\text { Equation (5) }\end{array}$ & $13.3 \%$ & $13.3 \%$ & $13.3 \%$ & $13.3 \%$ \\
\hline $\begin{array}{c}\text { Equivalent Circuit } \\
\text { Manufacturer Data }\end{array}$ & $14.1 \%$ & $13.9 \%$ & $14.1 \%$ & $14.1 \%$ \\
\hline $\begin{array}{c}\text { Equivalent Circuit } \\
\text { Measurement Data } \\
\text { Closed Configuration }\end{array}$ & $13.2 \%$ & $13.2 \%$ & $13.7 \%$ & $13.4 \%$ \\
\hline $\begin{array}{c}\text { Equivalent Circuit } \\
\text { Measurement Data } \\
\text { Open Configuration }\end{array}$ & $14.5 \%$ & $15 \%$ & $14.3 \%$ & $13.3 \%$ \\
\hline $\begin{array}{c}\text { Equivalent Circuit } \\
\text { Measurement Data } \\
\text { Tracker Configuration }\end{array}$ & $14.9 \%$ & $16 \%$ & $14.7 \%$ & $13.4 \%$ \\
\hline
\end{tabular}

The results for the calculated efficiencies in Table III show that the performance of the considered PV panel will be overestimated if the manufacturer's specification data is used to assess the efficiency of the panel installed in closed configuration (the difference over the range of considered input solar irradiance values is between $0.4 \%-0.9 \%$ ). The performance of the panel in closed configuration is correctly estimated with both analytical models, with differences in the range of $0.1 \%-0.4 \%$. On the other hand, calculated PV panel efficiencies for open and tracker configurations are higher than the efficiencies calculated using the manufacturer's specification data, except for $\mathrm{S}_{\text {irr }}=1000 \mathrm{~W} / \mathrm{m}^{2}$, when, as discussed previously, inverter limits the PV panel power output. The biggest differences are calculated for $\mathrm{S}_{\text {irr }}=600 \mathrm{~W} / \mathrm{m}^{2}$, when PV panel achieves $1.1 \%$ higher efficiency in open configuration and $2.1 \%$ higher efficiency in tracker configuration.

\section{CONCLUSIONS}

Two general models of PV systems and technologies are presented and discussed in this paper: an analytical model and an equivalent circuit model. Analytical model is formulated as the generic (i.e. average) performance model of the four main PV technologies currently available on the market, and is particularly suitable for the analysis of a large number of PV systems and installations. This model does not require any PV panel specific input data or parameters (except the type/technology of the panel), which allows to use it for a simple and correct representation of the aggregated power outputs of a specific mix of different PV technologies. On the other hand, equivalent circuit model requires specific input data and parameters, as well as the adjustment of the other model parameters, in order to provide an accurate representation of a modelled PV system. Due to its simplicity and ability to correctly represent different PV technologies, this model is one of the most commonly used, but its parameters are typically derived using the manufacturers' specification datasheets.

In order to clarify how equivalent circuit PV model can be used for the further analysis of the actual field PV applications and what adjustment, if any, would be required, the paper derived corresponding models of a selected PV panel using the manufacturer's specification data and actual field measurements. The differences in the calculated model parameters suggest that model based on the manufacturer's specification should be adjusted to correctly represent considered PV panel in all three configurations.

The analysis in the paper provides a direct comparison of the results for PV panel I-V characteristics, power outputs and efficiencies for different configurations. These results demonstrate that a correct PV model should take into account both the actual configuration of the panel and control of the inverter used for grid interconnection of the PV panel.

\section{REFERENCES}

[1] DECC, "UK Energy in Brief 2012", Department of Energy \& Climate Change, UK, 2012.

[2] DECC, "Energy trends: June 2012", Section 6 - Renewables, Department of Energy \& Climate Change, UK, 2012.

[3] G. N. Tiwari, S. Dubey, Fundamentals of Photovoltaic Modules and Their Applications, RSC Publishing, 2010.

[4] S. Z. Djokic and I. Papic, "Smart Grid Implementation of Demand Side Management and Micro-Generation", Int. Journal of Energy Optimization and Engineering, 1(2), 1-19, April-June 2012.

[5] M.G. Villalva, J.R. Gazoli, and E.R. Filho, "Comprehensive Approach to Modeling and Simulation of Photovoltaic Arrays", IEEE Trans. on Power Electronics, Nol. 24, No. 5, pp. 1198 -1208, May 2009.

[6] I. H.-Gil, I.-S. Ilie, and S. Z. Djokic, "Reliability Performance of Smart Grids with Demand-side Management and Distributed Generation/Storage Technologies", $3^{\text {rd }}$ IEEE European Conference on Innovative Smart Grid Technologies 2012, 14-17 Oct. 2012, Berlin, Germany.

[7] A. J. Collin, I. Hernando-Gil, J. L. Acosta, I.-S. Ilie, and S. Z. Djokic, "Realising the Potential of Smart Grids in LV Networks. Part 2: Microgeneration", $2^{\text {nd }}$ IEEE European Conference on Innovative Smart Grid Technologies, ISGT-EUROPE 2011, Manchester, UK, 5-7 Dec. 2011.

[8] A. J. Collin, J. L. Acosta, I. Hernando-Gil and S. Z. Djokic, “An 11kV Steady-State Residential Aggregate Load Model. Part 2: Microgeneration and Demand-side Management", IEEE PowerTech 2011, 19-23 June 2011, Trondheim, Norway.

[9] A. Gow and C. Manning, "Development of a photovoltaic array model for use in power-electronics simulation studies", IEE Proceedings on Elect. Power Appl., vol. 146, no. 2, pp. 193-200, 1999.

[10] M. Chegaar, Z. Ouennoughi, F. Guechi, and H. Langueur, "Determination of Solar Cells Parameters under Illuminated Conditions", Journal of Electron Devices, Vol. 2, pp. 17-21, 2003.

[11] D. Sera; R. Teodorescu, and P. Rodriguez, "PV panel model based on datasheet values", IEEE International Symposium on Industrial Electronics, ISIE 2007, pp. 2392-2396, 2007.

[12] A. El Tayyan, "PV system behavior based on datasheet", Journal of Electron Devices, Vol. 9, pp. 335-341, 2011.

[13] Yingli Solar, YL 180 P-23b Manufacturer Specification [Online]. Available: http://www.yinglisolar.com

[14] LEMCKO Energy and Power Quality Lab, "Elektrotechnical expertise centre of HOWEST", unpublished, measurements at a LEMCKO test PV site, 2011 and 2012.

[15] SMA SunnyBoy SB1100, Manufacturer Specification [Online]. Available: http://www.sma.de 